\title{
Trial of a single low dose of heparin in the prevention of post-operative deep-vein thrombosis monitored by doppler ultrasound
}

\author{
T. BATES \\ F.R.C.S.
}

Luton and Dunstable Hospital, Luton, Beds.*

\begin{abstract}
Summary
A consecutive, randomly allocated, controlled, doubleblind clinical trial of the prophylactic effect of a single pre-operative low dose of heparin on the incidence opost-operative deep-vein thrombosis showed no reducf tion in the number of thromboses detected.

Fifty-five patients were given $\mathbf{5 0 0 0}$ units of heparin subcutaneously 1-1 $\frac{1}{2} \mathrm{hr}$ pre-operatively and fifty-seven patients were given a placebo. The incidence of thrombosis detected by the doppler ultrasound was $14.5 \%$ in the heparin group and $12.3 \%$ in the control group.

It is suggested that a further trial monitored by ultrasound is indicated in which low-dose heparin is given for various periods post-operatively in addition to a pre-operative dose.
\end{abstract}

\section{Introduction}

Several trials have now shown that low-dose subcutaneous heparin is effective in reducing the incidence of post-operative calf-vein thrombosis (Sharnoff, Kass and Mistica, 1962; Kakkar et al., 1972; Williams, 1971; Gordon-Smith et al., 1972; Nicolaides et al., 1972). Sharnoff et al. (1962) first claimed that such a regime started pre-operatively reduced the thromboembolic complications of surgery. However, it is only recently that controlled trials (Kakkar et al., 1972; Williams, 1971; Gordon-Smith et al., 1972; Nicolaides et al., 1972) have produced evidence that prophylactic low-dose heparin significantly reduces the incidence of calf-vein thrombosis as indicated by the $I^{125}$ fibrinogen test. Although Nicolaides et al. (1972) have shown a reduction in the incidence of more extensive proximal venous thrombosis with this test, evidence that the number of fatal pulmonary emboli are reduced by low-dose heparin will require study of a large number of patients.

For this reason the doppler ultrasound technique (Rushmer, Baker and Stegall, 1966; Strandness et al., 1967; Sigel et al., 1968) was chosen to monitor the incidence of post-operative deep-vein thrombosis in a controlled trial of low-dose heparin since it is a relatively quick examination which does not require special staff. Furthermore, although this

\footnotetext{
*Present address: Department of Surgery, Guy's Hospital,
} London SE1 9RT. method does not detect calf-vein thrombosis, it has been shown to be reliable in detecting thrombus in the popliteal and more proximal veins (Sigel $e t$ al., 1968; Evans and Cockett, 1969). Evans (1971) found that the ileo-femoral segment is the most common source of fatal pulmonary emboli.

It has been shown that the majority of venous thromboses start during, or shortly after, operation (Flanc, Kakkar and Clarke, 1968) and Becker, Borgstrom and Saltzman (1970) found that heparin started post-operatively has no prophylactic effect. Most of the controlled trials (Kakkar et al., 1972; Williams, 1971; Nicolaides et al., 1972) have given heparin 5000 units subcutaneously 1 or $2 \mathrm{hr}$ preoperatively followed by the same dose 12 hourly for 5,7 or 10 days. However, Gordon-Smith et al. (1972) found no significant difference between those cases treated for 5 days post-operatively and those given only two post-operative doses. On the other hand Kakkar et al. (1971) in their first consecutive study continued the regime for 5 days but apparently left an interval of about $27 \mathrm{hr}$ between the pre-operative and first post-operative dose.

Calcium heparin (Calciparine, Choay) in a dose of 5000 units subcutaneously has been shown to give a low but significant plasma level of heparin for up to $12 \mathrm{hr}$ (Destaing et al., 1968). Since a single pre-operative dose of subcutaneous heparin appeared to be effective over the period of maximum risk it was felt justifiable to carry out a controlled trial. A single dose of heparin given with the premedication would be widely acceptable if effective and safe. Since it was hoped to include a large number of patients in this study it was decided to carry out a pilot study on a small number of high-risk patients.

\section{Patients and methods}

One hundred and twenty-two consecutive patients admitted to two general surgical wards for elective or emergency operations were studied. All patients were aged 40 years or over and had an abdominal operation (Table 1). They were admitted to a prospective, double-blind, randomized trial.

Seven patients who had an unequivocal previous history of deep-vein thrombosis or pulmonary 
TABLE 1. Types of operation performed

\begin{tabular}{lcc}
\hline \multicolumn{1}{c}{ Operations } & Control & Heparin \\
\hline Emergency operation & $8(0)$ & $12(2)$ \\
Gastric & $11(2)$ & $8(3)$ \\
Biliary & $16(1)$ & $15(3)$ \\
Colonic & $7(1)$ & $13(1)$ \\
Open prostatectomy & $8(1)$ & $6(0)$ \\
Renal & $7(1)$ & $5(0)$ \\
Laparotomy: miscellaneous & $8(1)$ & $8(1)$ \\
\hline
\end{tabular}

Figures in parentheses indicate number of patients with deep-vein thrombosis.

embolus were excluded from the trial and were given subcutaneous heparin 5000 units subcutaneously with the premedication and 12 hourly for 5 days postoperatively. Patients who had already had a minor operative procedure (such as a diagnostic cystoscopy) during the same admission were also excluded.

Previous episodes of probable deep-vein thrombosis or pulmonary embolus and the presence of obesity, varicose veins or malignancy or the recent taking of a contraceptive pill were recorded for each patient. The length of pre-operative hospital stay and the anaesthetic time for the operation were also recorded (Table 2). Both the control and test groups received the same routine physiotherapy.

\section{Design of the trial}

Each patient was randomly allocated, by the admitting nurse taking a trial form from an envelope, into one of four groups A, B, C or D. 200 ampoules were prepared and labelled, e.g. heparin A 5000 units in $0.2 \mathrm{ml}$. Ampoules $B$ and $D$ contained aqueous calcium heparin and ampoules $A$ and $C \stackrel{\mathbb{Q}}{\Omega}$ contained a placebo of similar appearance and $C$ consistency. An injection of $0.2 \mathrm{ml}$ was given $\overrightarrow{\overrightarrow{(}}$ subcutaneously into the anterior abdominal wall, as described by Griffith and Boggs (1964) at the same time as the premedication, though by a separate injection. The premedication was routinely given $1-1 \frac{1}{2} \mathrm{hr}$ pre-operatively.

Any excessive blood loss during or after surgery was recorded and the site of the heparin injection and $\vec{\circ}$ the wound were examined post-operatively for haematoma formation.

No coagulation study was carried out but the potency of the batch of calcium heparin used was checked at the beginning and the end of the trial by its effect on the kaolin-cephalin clotting-time of normal plasma.

\section{Diagnosis of deep-vein thrombosis}

All patients were examined pre-operatively and on 은 the second, fourth and sixth post-operative days using the Parkes Electronic Laboratories Model 802 Doppler Ultrasound instrument (frequency $10 \mathrm{MHz}$ ). If there was any reduction in the flow or clinical suggestion of a deep-vein thrombosis, examinationg were repeated until the patient's discharge. Audible signals from the Doppler were received through eate phones and the write-out was not used during this trial. A deep-vein thrombosis was diagnosed when there was reproduceable absence of an augmentation wave on squeezing the calf or lower thigh when the transducer was placed over the common femoral or

TABLE 2. Factors predisposing to deep-vein thrombosis

\begin{tabular}{|c|c|c|}
\hline & Control & Heparin \\
\hline \multicolumn{3}{|l|}{ Sex } \\
\hline Male & $32(3)$ & $27(4)$ \\
\hline Female & $25(4)$ & $28(4)$ \\
\hline \multicolumn{3}{|l|}{ Age (years) } \\
\hline Mean & 59 years & $63 \cdot 5$ years \\
\hline (range) & $(41-85)$ & $(40-96)$ \\
\hline $40-49$ & $13(1)$ & $10(1)$ \\
\hline $50-59$ & $17(2)$ & $12(1)$ \\
\hline $60-69$ & $18(4)$ & $18(3)$ \\
\hline $70-79$ & $8(0)$ & $11(3)$ \\
\hline $80-89$ & $1(0)$ & $3(0)$ \\
\hline $90+$ & 0 & $1(0)$ \\
\hline \multicolumn{3}{|l|}{ Predisposing factors } \\
\hline Varicose veins & $11(1)$ & $12(4)$ \\
\hline Obesity & $14(3)$ & $13(3)$ \\
\hline Malignancy & 14 (4) & $12(2)$ \\
\hline Previous deep-vein thrombosis & $4(0)$ & $5(1)$ \\
\hline Previous pulmonary embolus & 0 & $1(0)$ \\
\hline Contraceptive pill within 1 month & $1(0)$ & 0 \\
\hline Length of pre-operative stay-mean & $2 \cdot 6$ days & $\begin{array}{l}2 \cdot 6 \text { days } \\
(0-15)\end{array}$ \\
\hline Length of operation-mean & $1 \mathrm{hr} 40 \mathrm{~min}$ & $1 \mathrm{hr} 25 \mathrm{~min}$ \\
\hline (range) & $(15 \mathrm{~min}-3 \mathrm{hr})$ & $\left(1 \mathrm{hr} 25 \mathrm{~min}-3 \frac{1}{2} \mathrm{hr}\right)$ \\
\hline
\end{tabular}

Figures in parentheses indicates number of patients with deep-vein thrombosis. 
superficial femoral vein. The venous flow in the iliac veins and inferior vena cava was monitored by Valsalva variation in flow (Yao, Gourmos and Hobbs, . 1972).

The patients were also examined daily for clinical evidence of deep-vein thrombosis and the presence of tenderness or oedema in either leg was recorded. Phlebography was not generally available but those patients who died were submitted to careful post mortem examination for evidence of thromboembolic disease. Lung scans were not available but any episode suggestive of pulmonary embolus was recorded.

\section{Results}

One hundred and twenty-two patients were admitted to the trial but ten were subsequently excluded for the following reasons.

Three patients in the control group were excluded. One died $36 \mathrm{hr}$ post-operatively without a post mortem. One patient had a second operation after a week and then developed doppler evidence of a deepvein thrombosis. He subsequently had a minor pulmonary embolus. The third patient excluded from this group had a cardiac arrest on induction of anaesthesia for cholecystectomy. Sinus rhythm was restored after cardiac massage for $30 \mathrm{~min}$. She then had a large haematemesis and was given protamine since it was not at that time known which group she was in. This patient subsequently had an ileofemoral thrombosis.

Seven patients in the heparin group were excluded. Three had multiple operations but none developed evidence of thromboembolic complications. One patient was not given heparin with the premedication. One patient who had a superior mesenteric artery thrombectomy was given heparin 10,000 units intravenously at operation. She died due to re-thrombosis after $36 \mathrm{hr}$. Two patients in the heparin group had severe post-operative haemorrhage and were given protamine. One of these died $48 \mathrm{hr}$ after retropubic prostatectomy. This was a debilitated man of 82 . Bleeding stopped $12 \mathrm{hr}$ post-operatively but probably contributed to his death. The other patient required a second laparotomy for a haemoperitoneum $6 \mathrm{hr}$ after a sigmoid colectomy. There was widespread oozing in the pelvis. He subsequently died with intraabdominal sepsis and at post mortem had pelvic-vein thrombosis.

Of the remaining 112 cases, fifty-five were in the heparin group and fifty-seven in the control group. Eight $(14.5 \%)$ patients in the heparin group developed deep-vein thrombosis on doppler examination whereas thrombosis was detected in seven $(12.3 \%)$ in the control group. One patient in each group subsequently had clinical evidence of a minor pulmonary embolus (Table 3). Three patients in the
TABle 3. Frequency of deep-vein thrombosis

\begin{tabular}{ccccc}
\hline Group & D.V.T. & Minor P.E. & No D.V.T. & Total \\
\hline Control & $7(12 \cdot 3 \%)$ & 1 & 50 & 57 \\
Heparin & $8(14 \cdot 5 \%)$ & 1 & 47 & 55 \\
\hline
\end{tabular}

heparin group had a minor wound haematoma and one was noted to have increased bleeding from the wound at operation.

Analysis of the two groups showed that they were well-matched regarding factors known to predispose to the development of deep-vein thrombosis and the type of operations performed. The mean age in the heparin group was 63.5 years compared with 59 years in the control group. This was largely due to there being three more patients over 80 in the heparin group but none of these developed a deep-vein thrombosis. On the other hand the length of anaesthesia was slightly longer in the control group (Table 2).

None of the seven patients receiving heparin 5000 units 12-hourly for 5 days developed evidence of deep-vein thrombosis.

\section{Accuracy of the doppler in detection of deep-vein thrombosis}

Fifteen patients $(13 \%)$ in the present trial had evidence of a deep-vein thrombosis on doppler examination.

It was only possible to confirm these findings at post mortem in two cases and by phlebography in one. In a further six cases the patient subsequently developed clinical signs of a deep-vein thrombosis and two of these had a minor pulmonary embolus. However, in six patients (three from each group) the deep-vein thrombosis remained clinically silent and was not confirmed by phlebography.

In ten patients (six from the heparin group and four from the control group) there was a clinical suggestion of a deep-vein thrombosis but the doppler findings were persistently normal. None subsequently developed unequivocal physical signs or had a pulmonary embolus.

One patient in the trial who had previously had a deep-vein thrombosis complained of pain in the same calf post-operatively. Flow was reduced on doppler examination and it was thought that there might be a deep-vein thrombosis. Phlebography, however, showed no evidence of this.

One patient who was excluded from the trial was found to have pelvic-vein thrombosis although doppler findings in the legs were normal. The common and external iliac veins were not involved.

The doppler instrument was used to monitor the patients in the same surgical wards for 6 months before the trial and two false-positive diagnoses were made in moribund patients shortly before death. 
In both cases absence of flow appeared to be bilateral but post mortem examination showed no venous thrombosis. It is possible that circulatory collapse with severe venoconstriction may have accounted for this.

A further twenty-one patients have been examined in the medical wards following request to substantiate a clinical diagnosis of thromboembolic disease. Most of these patients were already anticoagulated. In twelve it was possible to support this diagnosis on doppler findings and in three of these cases this was confirmed at post mortem.

However, in the other nine patients no evidence of deep-vein thrombosis was found. In three this was confirmed at post mortem examination and one had normal phlebography. In the remaining five patients the diagnosis remained in doubt.

\section{Discussion}

The ultimate goal in the prophylaxis of postoperative deep-vein thrombosis is to prevent sudden death from a massive pulmonary embolus. Since this disaster is uncommon, any method of prevention would have to be widely accepted as safe and simple. The present pilot study of a single pre-operative low dose of subcutaneous heparin was made in an attempt to find the simplest possible regime by covering only the operation and the immediate post-operative period. Gordon-Smith et al. (1972) have already shown that by giving two further 12 hourly injections of heparin 5000 units the incidence of post-operative deep-vein thrombosis is significantly reduced. Although the present trial has been negative it seemed reasonable to carry out a pilot study of a single pre-operative dose before embarking on a large scale trial of a regime already shown to be effective (although monitored differently).

Sharnoff et al. (1962) hold that there is a second period of hypercoagulability during post-operative mobilization and for this reason advocate continued subcutaneous low-dose heparin treatment until the patient is fully mobile or discharged (Sharnoff and De Blasio, 1970). Both Kakkar et al. (1972) and Nicolaides et al. (1972) have recently reported that a small proportion of patients develop thrombosis in the late post-operative period. Nevertheless, prolonging the course of post-operative heparin is likely to reap diminishing returns and to be less widely acceptable.

Excessive bleeding has not been a major problem in most published series (Sharnoff et al., 1962; Kakkar et al., 1972; Williams, 1971; Gordon-Smith et al., 1972; Nicolaides et al., 1972) although there have been reports of massive wound haematomas after hip surgery (Charnley, 1972; Arden, Powell and Fell, 1972). Although it is not possible to say whether or not the post-operative bleeding in two patients in the present series was due to heparin, it seems possible that there is a small risk which should be considered when low-dose heparin is given.

Kakkar et al. (1972) have shown that plasma heparin levels after 5000 units subcutaneously $2 \mathrm{hr}$ pre-operatively, may fall much more rapidly after operation than was realized. It seems that in any future trial of low-dose heparin the second dose should be given within a few hours of operation. The best parameter for monitoring the effect of low-dose heparin has been the subject of some debate (Sharnoff, 1972; Eika, Godal and Kierulf, 1972; Bonnar, Denson and Biggs, 1972; Wessler et al., 1972), but as Bonnar et al. (1972) have pointed out, the ideal is a sufficient level of plasma heparin to potentiate the effect of antifactor $\mathrm{Xa}$ without producing incoagulable blood. No clotting-time was carried out in this series since only one dose of heparin was given. Most workers (Kakkar et al., 1972; Williams, 1971; Gordon-Smith et al., 1972; Nicolaides et al., 1972), with the exception of Sharnoff (1972), have found that 5000 units of heparin subcutaneously given 1-2 hr pre-operatively is a satisfactory initial dose. Calcium heparin was used in this trial since it was thought to be more satisfactory for subcutaneous injection However, it has recently been suggested that there is no difference between this and the more commonl used sodium heparin in terms of absorption or loca bleeding (Nicolaides et al., 1972).

Although Milne et al. (1971) cast some doubt on the reliability of the doppler technique in detecting deep-vein thrombosis, Sigel et al. (1968) found that compared with clinical examination the doppler was correct on phlebography in $83 \%$ of cases when the findings disagreed and in $96 \%$ of cases when they concurred. A similar degree of accuracy is reported by Evans and Cockett (1969) and this technique is being used increasingly to monitor post-operative surgical patients (McIlroy, 1972; Little and Binns, 1972). The incidence of doppler-detected post-operative deep-vein thrombosis in the present series was $13 \%$ which compares with an incidence of $5 \%$ found by McIlroy (1972) and one of between 30-6\% found by Little and Binns (1972). The $I^{125}$ fibrinogen test would be impractical in monitoring a large scale trial and the doppler technique would seem to be ideal, especially if facilities are available for confirming positive findings by phlebography.

This trial has certain defects in that an untried dose of heparin has been used with a new method of monitoring such a trial. The number of deep-vein thromboses in each group is relatively small and a much larger trial or one monitored by the $I^{125}$ fibrinogen test might show some benefit from heparin given as a single pre-operative dose. However, having completed this pilot study there would seem little point in continuing a larger study at this 
dosage. It is suggested that a further trial monitored by ultrasound using low-dose heparin for various periods post-operatively would be useful and should indicate the best regime for a large-scale trial in which prevention of fatal pulmonary emboli would be the criterion of success.

\section{Acknowledgments}

I wish to thank Mr M. H. Irving for advice in carrying out this trial and Mr R. V. Fiddian for permission to do studies on patients under his care and for his encouragement. I am most grateful to Dr Mary Houghton and Dr R. H. L. Down for doing many of the doppler examinations. I would also like to thank Mr S. Seligman for his help. I thank Choay Pharmaceuticals Ltd, Paris, for supplies of Calciparine Heparin and placebo, and $\mathrm{Mr}$ G. Thompson for arranging these supplies.

\section{References}

Arden, G.P., Powell, H.D.W. \& Fell, R.H. (1972) Subcutaneous heparin treatment. British Medical Journal, 4, 486.

Becker, J., Borgstrom, S. \& Saltzman, G.F. (1970) Incidence of thrombosis associated with epsilon-aminocaproic acid administration and with combined epsilon aminocaproic acid and subcutaneous heparin therapy. A clinical study with aid of intravenous phlebography. Acta Chirurgica Scandinavica, 136, 167.

Bonnar, J., Denson, K.W.E. \& Biggs, R. (1972) Subcutaneous heparin and prevention of thrombosis. Lancet, ii, 539.

Charnley, J. (1972) Prophylaxis of post-operative thromboembolism. Lancet, ii, 134.

Destaing, F., Chatelain, P., Portier, C., Lambert, D. \& Roque, G. (1968) Transcutaneous heparin therapy. Revue Medecine Dijon, 3, 409.

Eika, C., Godal, H.C. \& Kierulf, P. (1972) Detection of small amounts of heparin by the thrombin clotting-time. Lancet, ii, 376.

Evans, D.S. (1971) The early diagnosis of thromboembolism by ultrasound. Annals of the Royal College of Surgeons of England, 49, 225.

Evans, D.S. \& CocketT, F.B. (1969) Diagnosis of deep-vein thrombosis with an ultrasonic doppler technique. British Medical Journal, 2, 802.

Flanc, C., Kakkar, V.V. \& Clarke, M.B. (1968) The detection of venous thrombosis of the legs using $\mathrm{I}^{125}$, labelled fibrinogen. British Journal of Surgery, 55, 742.

Gordon-Smith, I.C., Grundy, D.J., LE Quesne, L.P., NewCOMBE, J.F. \& BRAMBLE, F.J. (1972) Controlled trial of two regimes of subcutaneous heparin in prevention of postoperative deep-vein thrombosis. Lancet, i, 1133.

Griffith, J.C. \& Boggs, R.B. (1964) The clinical usage of heparin. American Journal of Cardiology, 14, 39.

Kakkar, V.V., Corrigan, T., SPIndler, J., Fossard, D.P., Flute, T.P., Crellin, R.Q., Wessler, S. \& Yin, E.T. (1972) Efficacy of low doses of heparin in prevention of deep-vein thrombosis after major surgery. Lancet, ii, 101.

Kakkar, V.V., Field, E.S., Nicolaides, A.N., Flute, P.T., WESSLER, S. \& YIN, E.T. (1971) Low doses of heparin in prevention of deep-vein thrombosis. Lancet, ii, 669.

Little, J.M. \& BinNs, M. (1972) Spontaneous change in frequency of deep-vein thrombosis detected by ultrasound. Lancet, ii, 1229.

MCILROY, R.F. (1972) The routine use of ultrasound for the diagnosis of post-operative deep-vein thrombosis in a district general hospital. British Journal of Surgery, 59, 133.

Milne, R.M., Griffiths, J.M.T., GunN, A.A. \& Ruckley, C.V. (1971) Post-operative deep venous thrombosis. Lancet ii, 445.

Nicolaides, A.N., Dupont, P.A., Desai, S., Lewis, J.D., Douglas, J.N., Dodsworth, H., Fourides, G., Luck, R.J. \& JAMIESON, C.W. (1972) Small doses of subcutaneous sodium heparin in preventing deep venous thrombosis after major surgery. Lancet, ii, 890.

Rushmer, R.F., Baker, D.W. \& Stegall, H.F. (1966) Transcutaneous doppler flow detection as a non-destructive technique. Journal of Applied Physiology, 21, 554.

Sharnoff, J.G. (1972) Prevention of post-operative thrombosis. Lancet, i, 1398.

Sharnoff, J.G. \& De Blasio, G. (1970) Prevention of fatal post-operative thromboembolism by heparin prophylaxis. Lancet, ii, 1006.

Sharnoff, J.G., Kass, H.H. \& Mistica, B.A. (1962) A plan of heparinization of the surgical patient to prevent postoperative thromboembolism. Surgery, Gynaecology and Obstetrics 115, 75 .

Sigel, B., Popky, G., Wagner, D., Boland, J., Mapp, E. \& Feigl, P. (1968) A doppler ultrasound method for diagnosing lower extremity venous disease. Surgery, Gynaecology and Obstetrics, 127, 339.

Strandness, D.E. Jr, Schultz, R.D., Sumner, D.S. \& RUSHMER, R.F. (1967) Ultrasonic flow detection. A useful technique in evaluation of peripheral vascular disease. American Journal of Surgery, 113, 311.

Wessler, S., Yin, E.T., Flute, P.T. \& KakKar, V.V. (1972) Thrombin-time test. Lancet, ii, 877.

Williams, H.T. (1971) The prevention of post-operative deep-vein thrombosis with perioperative subcutaneous heparin. Lancet, ii, 950.

YAO, S.T., Gourmos, C. \& Hobrs, J.T. (1972) Detection of proximal-vein thrombosis by doppler ultrasound flowdetection method. Lancet, $\mathrm{i}, 1$. 